\title{
Capsule endoscopy in the assessment of iron deficiency anaemia and obscure gastrointestinal bleeding Wickramasinghe D.P, MBBS ${ }^{1}$,Gunarathna I.N, MBBS $^{1}$, Samarasekera D.N, MBBS, MD, MS,FRCS(Ed.\&Eng.) ${ }^{2}$ \\ 1 Research Assistant, University Surgical Unit, The National Hospital of Sri Lanka. \\ 2 Professor of Surgery,University Surgical Unit, The National Hospital of Sri Lanka.
}

\begin{abstract}
Introduction: Capsule endoscopy (CE) was introduced in the year 2000 for visualizing the gastrointestinal (GI) tract and since then it has played an important role in the assessment of patients with obscure GI bleeding (OGIB) and unexplained iron deficiency anaemia (IDA).
\end{abstract}

Methods: The aim of this study was to describe the usefulness of CE in the assessment of OGIB and IDA. We analysed the demographical and medical conditions of these patients and the diagnostic yield of CE and its impact on patient management.

Results: Of the 22 patients, 12 were male. Mean age was $50.7(\mathrm{SD}=19.6$ years, Range= 20-81) years. The majority $(n=11)$ referred were being investigated for unexplained iron deficiency anaemia. Other indications were, OGIB $(n=6)$, melaena $(n=4)$, malabsorption and IDA $(n=1)$ and massive GI bleed $(\mathrm{n}=1)$. CE showed no abnormalities in 7, polyps and helminthiasis were identified in 2 patients each. Multiple other pathologies were also identified in the remaining. In $91.3 \%(n=21)$ it provided new information and in $83.3 \%(n=20)$ it provided the information sought by the doctor. In $79.2 \%(n=19)$ it changed the management.

Conclusion: Though the cost of CE is significantly high compared to other GI investigations, the high diagnostic yield and its impact on patient management justified its use.

Key words: Anaemia; Obscure gastro intestinal bleeding; Capsule endoscopy.

\section{Introduction}

Capsule endoscopy (CE) is a novel method of visualizing the digestive tract and this procedure was first introduced in 2000 [1]. The camera module, batteries and the transmitter are all encased inside a $11 \times 30 \mathrm{~mm}$ capsule which is propelled through the gastro intestinal (GI) tract by peristalsis and does not need air insufflation. The technical details [1] and the procedure [2] are described elsewhere. Since its introduction, it has revolutionized the investigation of occult gastro intestinal bleeding (OGIB) [3,4], polyposis

Correspondence: D.N. Samarasekera, University Surgical Unit,

The National Hospital of Sri Lanka.

Email: samarasekera58@yahoo.co.uk

The Sri Lanka Journal of Surgery 2011; 29(1):23-27. syndromes [5], Crohn's disease [6], Iron deficiency anemia (IDA) [7] and virtually any conditions that require visualizing the small intestine (SI).

OGIB is defined as recurrent or persistent gastrointestinal (GI) bleeding in the absence of any positive findings at initial upper and lower GI endoscopy [8]. This is further divided into 2 groups depending on the presence or absence of overt bleeding; i.e. clinically evident passage of blood from the GI tract (Obscure Overt GI bleeding, OGIB-Overt) or faecal occult blood being positive and/or iron deficiency anaemia in the absence of overt bleeding (Obscure Occult GI bleeding, OGIB-Occult).

IDA can be caused by many causes, and GI bleeding is one of the common and more sinister 
causes of it. Since obvious or overt GI bleeding can result in IDA, if the cause persists, the two are considered together in the evaluation of the efficacy ofCE.

Several authors have reported a diagnostic yield of $60-70 \%$ for CE in the evaluation of OGIB [3,912], both in the west as well as in the east. Significant variations exist in the diagnostic yield, especially depending on whether the patient has overt or occult bleeding [13].

The aim of this study was to describe,

i) the different causes of OGIB in the cohort of patients referred and,

ii) the diagnostic yield of $\mathrm{CE}$ in evaluating patients with OGIB.

\section{Material and Methods}

\section{Population and sample}

Twenty two consecutive patients who were referred for CE to the GI Physiology Laboratory of the Department of Surgery, Faculty of Medicine, University of Colombo for CE for the investigation of OGIB or IDA were included in the study. Socio-demographic and other relevant clinical data were collected using a proforma. In addition, they underwent upper GI endoscopy and colonoscopy at our unit if those examinations had not been done at the time of the referral. If there was any suspicion of intestinal strictures, they underwent barium meal and follow through prior to $\mathrm{CE}$.

The study was approved by the Ethical Review Committee of the National Hospital of Sri Lanka.

\section{Equipment}

$\mathrm{CE}$ was performed using the PilCam system (Given Imaging, Yokneam, Israel) using the SB2 (small bowel) and COLON capsules. The capsule weighs $3.7 \mathrm{~g}$ and takes two photographs every second in a $140^{\circ}$ field of view and 8:1 magnification.

\section{Procedure}

Capsule endoscopy was carried out after an overnight fast and bowel preparation with 4 sachets of polyethylene glycol for the small bowel (SB) and 5 sachets for colonic CE. Abdominal hair was shaved as this would interfere with sensor placement. The receiver was worn in the belt provided. Participants swallowed the respective capsule with a glass of water. They were asked to remain fasting for 4 more hours, after which time the capsule position was confirmed by using the real time viewer. If the capsule had passed the pylorus, they were allowed sips of water immediately and a snack of 2 biscuits 2 hours after. High fiber and coloured food was avoided for the entire duration of the procedure. The recording continued till the depletion of the battery or until the caecum was visualized, whichever came first. After completion, the data were downloaded to a computer using the software provided (Rapid Reader, Given Imaging, Yokneam, Israel) and reviewed and analyzed by the 2 authors.

\section{Results}

There were 22 patients $(\mathrm{M}: \mathrm{F}=12: 10)$ who underwent $\mathrm{CE}$ as a part of their evaluation for OGIB or IDA. Mean age was 50.7 years $(\mathrm{SD}=19.6$ years, Range $=20-81)$ years. A total of $24 \mathrm{CE}$ were done (22 SB, 2 colon) in 22 patients. None needed the procedure to be repeated or endoscopic insertion of the capsule. Since the 2 patients who underwent colonic $\mathrm{CE}$ also underwent small bowel $\mathrm{CE}$, the data given below are for small bowel CE unless otherwise specified. The commonest indication was IDA $(n=10)$, followed by OGIB $(n=6)$, melaena $(n=4)$ and 1 each for massive endoscopy negative upper GI bleeding and malabsorption. 8 procedures were terminated by the operator while the remaining 14 ended when the battery of the capsule was depleted. There was only 1 incomplete study where the capsule was stuck in a diverticulum in the stomach and this was the only adverse effect observed. The oesophageal, stomach, SB and total transit times (mean SD) were $7.9 \mathrm{~s} 16.5 \mathrm{~s}$, 40.146 .2 minutes, $258.3 \quad 128.3$ minutes and 633.7220 .6 minutes respectively. The duodenal papilla, oesophago-cardiac junction and appendix were identified in [number (percentage)] $2(9.5 \%)$, $3(14.3 \%)$ and $7(31.8 \%)$ patients. FICE (Fuji Intelligent Chromo Endoscopy) was used in 13 patients.

Helminthiasis (Figure 1), ileal ulceration (Figure $2)$, jejunal erosions, prominent intestinal vasculature and intestinal polyposis (Figure 3) were detected in 2 patients each. One patient each had angiodysplasia, ileal mucosal changes, combined ileal and jejunal erosions, gastric erosions (Figure 4) and gastric mucosal abnormalities. 


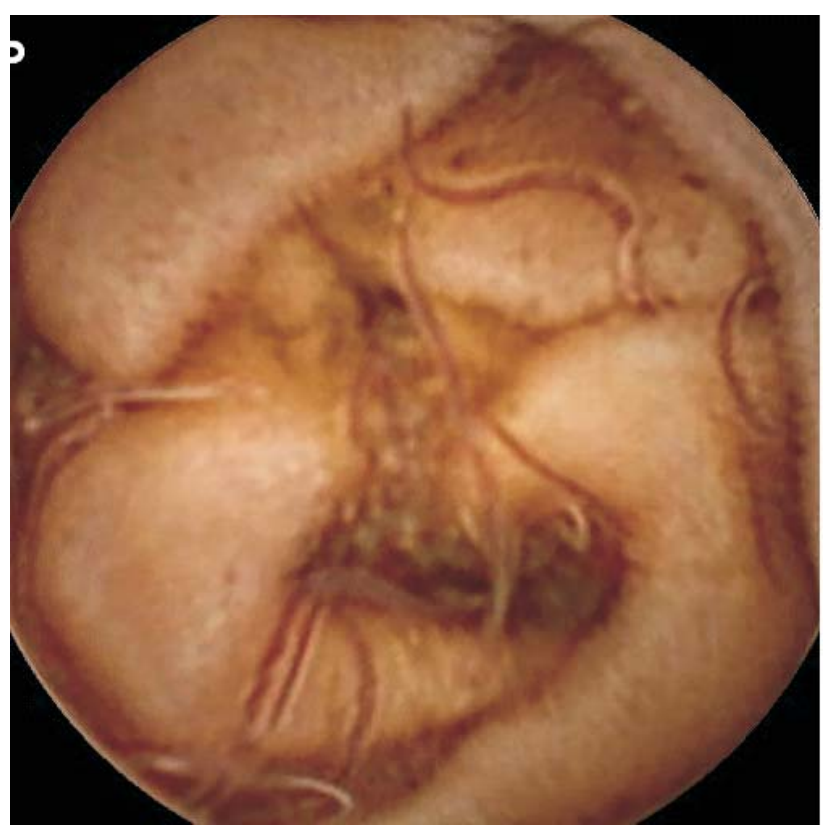

Figure 1. Helminthiasis

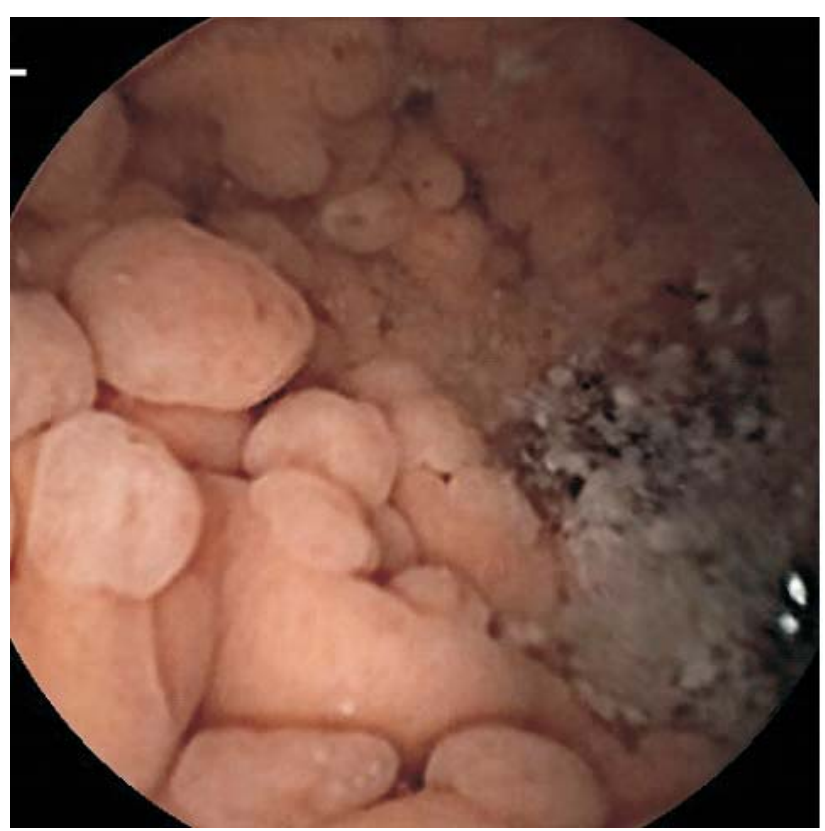

Figure 3. Polyposis syndrome

In $7(31.8 \%)$ patients, no abnormalities were detected.

In total, CE provided new information in 20 $(90.9 \%)$ patients, provided the information sought by the doctor in $19(86.4 \%)$ patients and changed the management in $18(81.8 \%)$ patients. All patients swallowed the capsule easily and none reported any discomfort during the procedure

Of the 2 patients who additionally underwent colon $\mathrm{CE}$, in 1 patient $\mathrm{CE}$ provided new

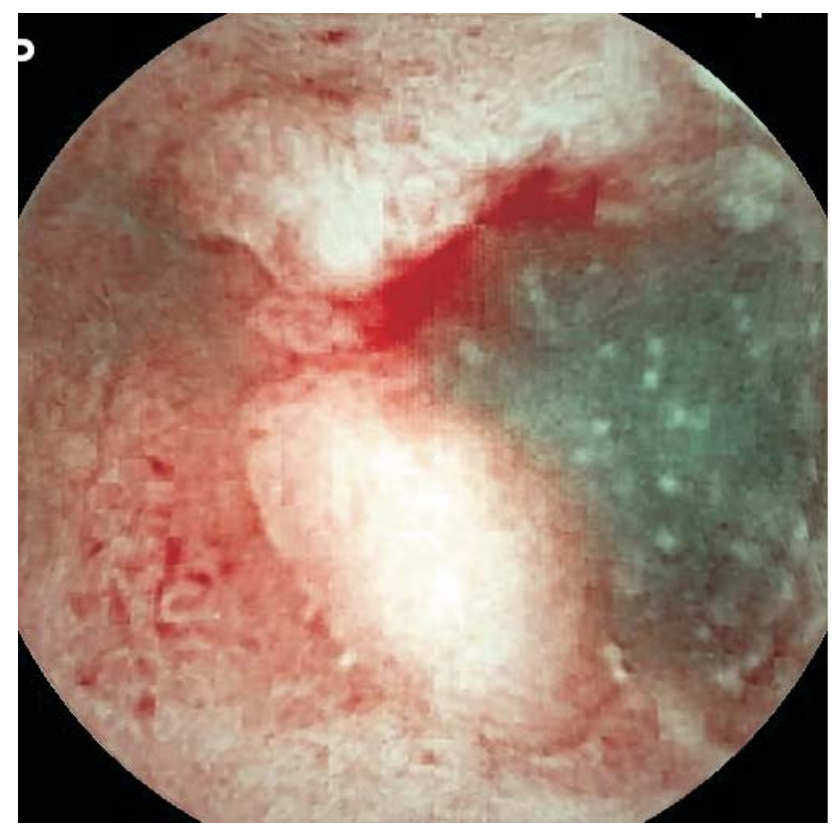

Figure 2. Ileal ulceration

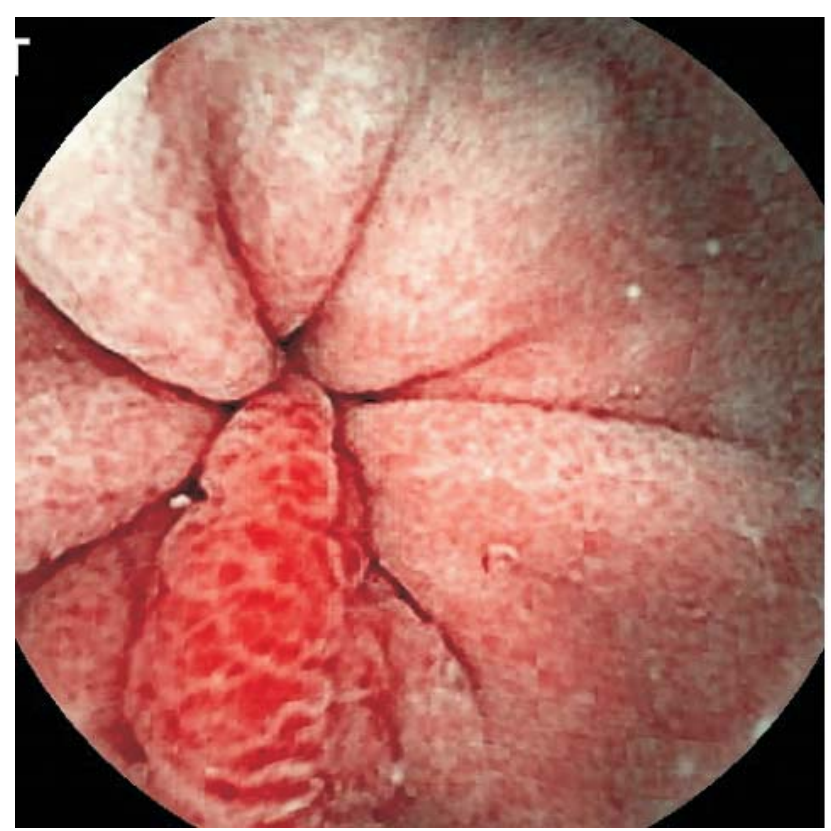

Figure 4. Gastric erosions

information, the information sought by the doctor and changed the management.

\section{Discussion}

OGIB was previously a difficult condition to investigate, especially due to the length of the SB but the introduction of $\mathrm{CE}$ made visualization of the SB much more simpler. A general consensus exists that $\mathrm{CE}$ has a high diagnostic yield with success values varying from $55 \%$ [11] to $92 \%$ 
[13]. The studies carried out among patients in the west have reported higher diagnostic yield for OGIB-overt compared to OGIB-occult (92.3\% vs. 44.2\%)[13]. Studies carried out among Asian patients have contradicting results with studies favouring [14] as well as contradicting [3] this fact. In our study, CE managed to provide new information in $90.9 \%$ of patients, which is comparable with previous reported values. We considered both positive and negative findings as new information, as an entirely normal capsule endoscopy changed the line of investigation and management of the patient.

The presence of helminthiasis in patients is an expected finding in the tropics. Several previous authors have reported hookworm infestations $[15,16]$ and controversial reports of Ascaris lumbricoides as a cause of IDA [17]. However, given the cost of the equipment and the prevalence of worm infestations in Sri Lanka, we would like to suggest a course of Antihelminthics (e.g. Mebendazole) for any patient who is referred for $\mathrm{CE}$ as a part of the evaluation for unexplained IDA.

The main limitation in our study was that we did not have facilities to visualize the SB using other modalities such as double balloon enteroscopy which is considered the gold standard for investigating the SB [18]. Two other limitations were the high cost and poor image quality due to faecal residue. We feel the latter may be because of the different dietary habits of the Asian population and this factor may be prevented by advising a low residue diet for 3 days preceding the CE.

In conclusion, we found $\mathrm{CE}$ to be a safe and an effective investigation in the assessment of the SB in patients with OGIB and IDA with a high diagnostic yield. It also had a significant impact on the patient management.

\section{References}

1. Iddan G, Meron G, Glukhovsky A, and Swain P, Wireless capsule endoscopy. Nature, 2000;405(6785):417.

2. Delvaux M, and Gay G, Capsule endoscopy: technique and indications. Best
Pract Res Clin Gastroenterol, 2008;22(5):813-37.

3. Ghoshal UC. Lakshmi CP, Kumar S, K. Das K, Misra A, Rai P, Mohindra S, Saraswat VA, Kumar A, and Choudhuri G, Capsule endoscopy for obscure gastrointestinal bleeding in the tropics: report from India. Dig Endosc, 2011; 23(1):17-23.

4. Goenka MK, Majumder S, Kumar S, Sethy PK and Goenka U, Single center experience of capsule endoscopy in patients with obscure gastrointestinal bleeding. World J Gastroenterol, 2011; 17(6):774-8.

5. Tescher P, Macrae FA, Speer T, Stella D, Gibson R, Tye-Din JA, Srivatsa G, Jones IT, and Marion K, Surveillance of FAP: a prospective blinded comparison of capsule endoscopy and other GI imaging to detect small bowel polyps. Hered Cancer Clin Pract, 2010;8(1):3.

6. Lucendo AJ, and Guagnozzi D. Small bowel video capsule endoscopy in Crohn's disease: What have we learned in the last ten years? World J Gastrointest Endosc, 2011; 3(2):23-9.

7. Sheibani S, Levesque BG, Friedland S, Roost J, and Gerson LB, Long-term impact of capsule endoscopy in patients referred for iron-deficiency anemia. Dig Dis Sci, 2010;55(3):703-8.

8. Zuckerman, G.R., C. Prakash, M.P. Askin, and B.S. Lewis, $A G A$ technical review on the evaluation and management of occult and obscure gastrointestinal bleeding. Gastroenterology, 2000;118(1): p. 201-21.

9. Albert JG, Schulbe R, Hahn L, Heinig D, Schoppmeyer K, Porst H, Lorenz R, Plauth M, Dollinger MM, Mossner J, Caca K, and Fleig WE, Impact of capsule endoscopy on outcome in mid-intestinal bleeding: a multicentre cohort study in 285 patients. Eur J Gastroenterol Hepatol, 2008; 20(10): p. 971-7.

10. Appleyard M, Fireman Z, Glukhovsky A, Jacob H, Shreiver R, Kadirkamanathan S, Lavy A, Lewkowicz S, Scapa E, Shofti R, Swain P, and Zaretsky A. A randomized 
trial comparing wireless capsule endoscopy with push enteroscopy for the detection of small-bowel lesions. Gastroenterology, 2000;119(6):1431-8.

11. Lewis BS, and Swain P. Capsule endoscopy in the evaluation of patients with suspected small intestinal bleeding: Results of a pilot study. Gastrointest Endosc, 2002; 56(3):349-53.

12. Scapa E, Jacob H, Lewkowicz S, Migdal M, Gat D, Gluckhovski A, Gutmann N, and Fireman Z. Initial experience of wirelesscapsule endoscopy for evaluating occult gastrointestinal bleeding and suspected small bowel pathology. Am J Gastroenterol, 2002; 97(11):2776-9.

13. Pennazio M, Santucci R, Rondonotti E, Abbiati C, Beccari G, Rossini FP, and De Franchis R. Outcome of patients with obscure gastrointestinal bleeding after capsule endoscopy: report of 100 consecutive cases. Gastroenterology, 2004;126(3):643-53.

14. Gupta R, Lakhtakia S, Tandan M, Banerjee
R, Ramchandani M, Anuradha S, Ramji C, Rao GV, Pradeep R, and Reddy DN, Capsule endoscopy in obscure gastrointestinal bleeding--an Indian experience. Indian $\mathrm{J}$ Gastroenterol, 2006;25(4):188-90.

15. Kalli T, Karamanolis G, and Triantafyllou K. Hookworm infection detected by capsule endoscopy in a young man with iron deficiency. Clin Gastroenterol Hepatol, 2011; 9(4): e33.

16. Christodoulou DK, Sigounas DE, Katsanos KH, Dimos G, and Tsianos EV. Small bowel parasitosis as cause of obscure gastrointestinal bleeding diagnosed by capsule endoscopy. World J Gastrointest Endosc, 2010;2(11):369-71.

17. Visser L, and Lieshout L. Unexpected cause of iron deficiency detected by capsule endoscopy. Neth J Med, 2009;67(9): 317; author reply 317 .

18. Gerson LB, Double-balloon enteroscopy: the new gold standard for small-bowel imaging? Gastrointest Endosc, 2005; 62(1):71-5. 